\title{
EVALUATION OF SOME BASIC TRAITS OF A PROMISING COCONUT HYBRID: SRI LANKAN GREEN DWARF CROSSED TO VANUATU TALL (SGD x VTT)
}

\author{
D. Dare ${ }^{1}$, E. Andoh-Mensah, J. Owusu-Nipah, N. Yankey, R. N. Quaicoe, J. Nkansah-Poku \\ and S. K. Dery \\ CSIR- Oil Palm Research Institute, Coconut Programme, P. O. Box 245, Sekondi \\ le-mail: ghanabadare@yahoo.com
}

\begin{abstract}
The Lethal Yellowing Disease locally referred to as the "Cape St Paul Wilt Disease" is the single most important disease that has devastated several hectares of coconut plantations in Ghana. Two decades of coconut screening for tolerant planting material has identified the Sri Lankan Green Dwarf crossed Vanuatu Tall (SGD $x$ VTT) coconut hybrid as the most promising planting material in the context of disease. To provide farmers with planting material that has high disease tolerance and also good agronomic characteristics, the study compared some basic traits of the coconut hybrid with other important coconut varieties with the objective of determining the suitability of the SGD $x$ VTT as alternative planting material to revamp the coconut industry in Ghana. Mean sample size of 25 palms per coconut variety under the study was analyzed using two sample t-test procedure. The study indicated that the yield performance of the SGD $x$ VTT coconut hybrid was better than the tall coconut types including the local West African Tall (WAT) and compared favourably with the Malayan Yellow Dwarf crossed Vanuatu Tall (MYD $x$ $V T T)$ coconut hybrid. The good agronomic characteristics of the SGD $x$ VTT coupled with its high resistance to the CSPWD proved its suitability as alternative planting material to revamp the coconut industry in Ghana.
\end{abstract}

Keywords: Lethal yellowing; Cape St. Paul Wilt disease; SGD x VTT coconut hybrid; Resistant coconut hybrid; MYD x VTT coconut hybrid

\section{INTRODUCTION}

The coconut palm, Cocos nucifera L., is an important crop in the economies of the coastal areas of Ghana (Ofori and Nkansah-Poku, 1997). About $4.2 \%$ of the population of Ghana depends on coconut for their livelihood (Adams et al., 1996). In the Western Region, it is estimated that $20 \%$ of the rural dwellers depend on coconut for sustenance (Adams et al., 1996). Notwithstanding these important contribu- tions, several factors impact negatively on coconut production; prominent among them is the Lethal Yellowing Disease known locally as "Cape St Paul Wilt Disease" (CSPWD). The use of resistant coconut varieties has been identified as the best way of controlling the disease (Dery et al., 2008). Two decades of coconut screening for tolerant planting material has identified the Sri Lankan Green Dwarf crossed Vanuatu Tall (SGD x VTT) coconut hybrid as 
10

\section{Dare et al.}

the most promising planting material among Malayan Yellow Dwarf crossed Vanuatu Tall (MYD x VTT), Sri Lanka Green Dwarf (SGD), Vanuatu Tall (VTT) and the local West African Tall (WAT) which have varying levels of resistance to the CSPWD (Dery et al., 1997; Dery, et al., 2008). The MYD x VTT was used by the Coconut Sector Development Project for a replanting programme from 1999 to 2005 partly due to its good agronomic characteristics but succumbs under high disease pressure (Dery et al., 2008). The local WAT coconut, highly preferred by farmers for its agronomic characteristics, is very susceptible to the disease. To provide farmers with planting material that has high disease tolerance and also good agronomic characteristics, the study compared some basic traits of the coconut hybrid with other important coconut varieties with the objective of determining the suitability of SGD $x$ VTT as alternative planting material to revamp the coconut industry in Ghana.

\section{MATERIALS AND METHODS}

The study was carried out in the coconut belt of south western Ghana on existing plots of Vanuatu Tall (VTT), Sri Lankan Green Dwarf (SGD), Malayan Yellow Dwarf crossed Vanuatu Tall (MYD x VTT) and Sri Lankan Green Dwarf crossed Vanuatu Tall (SGD x VTT) coconut varieties established between 1981 and 1983 with the latter in 1995. The VTT (tall coconut type) was planted at $9.0 \mathrm{~m}$ triangular spacing at a density of 143 palms ha $^{-1}$ while SGD (dwarf coconut type) was planted at $8.0 \mathrm{~m}$ triangular spacing at a density of 180 palms ha $^{-}$

1 . Both MYD x VTT and SGD x VTT coconut hybrids were planted at $8.5 \mathrm{~m}$ triangular at a density of 158 palms ha $^{-1}$. Mean sample size was 25 palms per coconut variety.

Immature nuts were visually observed for their colour. Size of dry nut was determined according to the following criteria: (a) nut $\leq 300 \mathrm{~g}=$ small (b) $300 \mathrm{~g}<$ nut $<800 \mathrm{~g}=$ medium (c) nuts $\geq 800 \mathrm{~g}=$ large. Nut yield was determined at a six - monthly interval by nut count on bunches subtended by leaf ranks 14, 19 and 24 . The number of nuts in the three bunches were aver-

aged and the mean multiplied by 12 to estimate nut load palm $^{-1}$ year $^{-1}$ (Santos et al., 1996). Two dry fruits per study palm were sampled to determine mean weights of whole nut, husk, shell, meat and water components and also weight of copra using the techniques described by Santos et al. (1996).

Plant density of coconut variety was multiplied by nut load palm ${ }^{-1}$ year $^{-1}$ to derive nut yield ha 1. Copra weight nut $^{-1}$ was multiplied by nut load palm $^{-1}$ year ${ }^{-1}$ to obtain copra yield palm $^{-1}$ year ${ }^{-1}$ and then multiplied by plant density of coconut variety to derive copra yield $\mathrm{ha}^{-1}$ year $^{-1}$. Existing data on the local West African Tall (WAT) coconut variety (Andoh-Mensah et. al., 2003) and flowering of the coconut varieties were incorporated into the study. Data was analyzed using two sample t-test procedure of Genstat statistical software. Standard error of the mean difference was used to estimate least significant differences $(\mathrm{P}<0.05)$.

\section{RESULTS \& DISCUSSION}

\section{Time to flowering and nut features}

The dwarf variety (SGD) flowered four years earlier and became harvestable three years earlier than the tall varieties (WAT and VTT). The hybrids: SGD x VTT and MYD x VTT flowered 1 year later than the dwarf but were harvestable at the same time as the dwarf (Table 1). Early inflorescence emergence and fruit bearing are characteristics features of dwarf coconut types (FAO, 1975; Ohler and Magat, 2001). The variable nut colour and size in the tall and hybrid coconut varieties did not only suggest dominance of the tall varieties for nut colour and size but also pointed to the existence of sub-populations within the tall and hybrid coconut types. Breeding and molecular biology techniques could be used to identify the various sub-populations within the tall and hybrid varieties (Bourdeix, 1999). The uniform nut colour and size in the dwarf was largely due to self pollination in the variety (Ohler and Magat, 2001). 
Time 1: Time to flowering and nut features of SGD x VIT and other important coconut varieties

\begin{tabular}{|c|c|c|c|c|c|}
\hline $\begin{array}{l}\text { Flowering \& } \\
\text { Nut Features }\end{array}$ & SGD $x$ VTT & MYD x VTT & SGD & VTT & WAT \\
\hline $\begin{array}{l}\text { Time to flow- } \\
\text { ering (yrs) }\end{array}$ & $3-4$ & $3-4$ & $2-3$ & $6-7$ & $6-7$ \\
\hline $\begin{array}{l}\text { Time to first } \\
\text { harvest (yrs) }\end{array}$ & 4 & 4 & 4 & 7 & 7 \\
\hline $\begin{array}{l}\text { Nut colour } \\
\text { (Immature) }\end{array}$ & $\begin{array}{l}\text { Green } \\
\text { Red } \\
\text { Bronze }\end{array}$ & $\begin{array}{l}\text { Green } \\
\text { Red } \\
\text { Bronze }\end{array}$ & Green & $\begin{array}{l}\text { Green } \\
\text { Red } \\
\text { Bronze }\end{array}$ & $\begin{array}{l}\text { Green } \\
\text { Red } \\
\text { Bronze }\end{array}$ \\
\hline $\begin{array}{l}\text { Nut size } \\
\text { (mature) }\end{array}$ & $\begin{array}{l}\text { Small } \\
\text { Medium } \\
\text { Large }\end{array}$ & $\begin{array}{l}\text { Small } \\
\text { Medium } \\
\text { Large }\end{array}$ & Medium & $\begin{array}{l}\text { Small } \\
\text { Medium } \\
\text { Large }\end{array}$ & $\begin{array}{l}\text { Small } \\
\text { Medium } \\
\text { Large }\end{array}$ \\
\hline
\end{tabular}

Nut and copra yield

The nut and copra yield of SGD x VTT hybrid were respectively $12 \%$ and $42 \%$ significantly $(\mathrm{p}<0.05)$ lower than that of MYD x VTT but
$34 \%$ and $43 \%$ significantly $(\mathrm{p}<0.05)$ higher than nut and copra yield of WAT or VTT (Table 2).

Table 2: Nut and copra yield potential of SGD x VTT and other important coconut varieties

\begin{tabular}{|c|c|c|c|c|c|}
\hline \multirow[t]{2}{*}{ Variety } & \multicolumn{5}{|c|}{ Yield Potential } \\
\hline & $\begin{array}{l}\text { Nut palm } \\
(\mathrm{nb})\end{array}$ & $\begin{array}{l}\text { Nut ha }{ }^{-1} \mathrm{yr}^{-1} \\
(\mathrm{nb})\end{array}$ & $\begin{array}{c}\text { Copra nut } \\
\text { (g) }\end{array}$ & $\begin{array}{c}\text { Copra palm } \\
\text { yr- }^{-1}(\mathrm{~kg})\end{array}$ & $\begin{array}{c}\text { Copra ha }{ }^{-1} \mathrm{yr}^{1} \\
\text { (ton) }\end{array}$ \\
\hline SGD x VTT & $\begin{array}{c}137^{\mathrm{b}} \\
( \pm 2.7)\end{array}$ & $\begin{array}{l}21,646^{\mathrm{b}} \\
( \pm 427)\end{array}$ & $\begin{array}{c}167^{\mathrm{b}} \\
( \pm 9.6)\end{array}$ & $\begin{array}{l}22.9^{b} \\
( \pm 0.5)\end{array}$ & $\begin{array}{c}3.6^{\mathrm{b}} \\
( \pm 0.1)\end{array}$ \\
\hline MYD x VTT & $\begin{array}{c}154^{\mathrm{a}} \\
( \pm 5.5)\end{array}$ & $\begin{array}{c}24,316^{\mathrm{a}} \\
( \pm 876)\end{array}$ & $\begin{array}{r}212^{\mathrm{a}} \\
( \pm 2.7)\end{array}$ & $\begin{array}{c}32.6^{\mathrm{a}} \\
( \pm 1.2)\end{array}$ & $\begin{array}{c}5.2^{\mathrm{a}} \\
( \pm 0.2)\end{array}$ \\
\hline SGD & $\begin{array}{c}143^{\mathrm{b}} \\
( \pm 6.0)\end{array}$ & $\begin{array}{l}25,812^{a} \\
( \pm 1,089)\end{array}$ & $\begin{array}{c}148^{\mathrm{b}} \\
( \pm 11.0)\end{array}$ & $\begin{array}{l}21.1^{\mathrm{bc}} \\
( \pm 1.6)\end{array}$ & $\begin{array}{c}3.8^{\mathrm{b}} \\
( \pm 0.1)\end{array}$ \\
\hline VTT & $\begin{array}{c}96^{\mathrm{c}} \\
( \pm 12.3)\end{array}$ & $\begin{array}{l}13,680^{c} \\
( \pm 1,761)\end{array}$ & $\begin{array}{c}166^{b} \\
( \pm 3.6)\end{array}$ & $\begin{array}{l}16.1^{\mathrm{c}} \\
( \pm 2.1)\end{array}$ & $\begin{array}{c}2.3^{\mathrm{c}} \\
( \pm 0.3)\end{array}$ \\
\hline WAT & $\begin{array}{c}91^{\mathrm{c}} \\
( \pm 2.0)\end{array}$ & $\begin{array}{l}13,424^{\mathrm{c}} \\
( \pm 291)\end{array}$ & $\begin{array}{c}220^{\mathrm{a}} \\
( \pm 12.3)\end{array}$ & $\begin{array}{c}16.8^{\mathrm{c}} \\
( \pm 1.1)\end{array}$ & $\begin{array}{c}2.4^{\mathrm{c}} \\
( \pm 0.2)\end{array}$ \\
\hline $\operatorname{LSD}_{0.05}$ & 7.3 & 1,502 & 19.3 & 5.2 & 0.71 \\
\hline
\end{tabular}

Means in the same column followed by the same letter (s) are not significantly different $(\mathrm{P}<0.05)$. 


\section{Dare et al.}

The high yield potential of the hybrids relative to the tall coconut types could be attributed to precocity conferred on the hybrids by their dwarf parents (Bourdeix, 1999; Ohler and Magat, 2001). The SGD x VTT yield performance was not significantly $\quad(p<0.05)$ different from its SGD dwarf parent except for nut yield ha $^{-1}$ which was $16.1 \%$ significantly $(\mathrm{p}<0.05)$ lower; attributable to a higher plant density for SGD (180 palms ha ${ }^{-1}$ ) compared with 158 palms ha ${ }^{-1}$ for SGD x VTT.

\section{Fruit Composition}

Meat weight per nut for SGD x VTT was not different from that of MYD $x$ VTT but was $14 \%, 24 \%$ and $107 \%$ significantly $(\mathrm{P}<0.05)$ higher than meat weight per nut for VTT, WAT and SGD, respectively (Table 3). Similarly, water weight per nut for SGD x VTT was not different from that of MYD $x$ VTT but was $79 \%, 130 \%$ and $455 \%$ significantly $(\mathrm{P}<0.05)$ greater than water weight per nut for VTT,
WAT and SGD, respectively. The synergy observed in the SGD x VTT coconut hybrid relative to its dwarf parent (SGD) and tall parent (VTT) suggested hybrid vigour in the SGD $x$ VTT coconut hybrid (FAO, 1975; Bourdeix, 1999). Differences in shell weight between the hybrids and the talls were not significant $(p<0.05)$ but the shell for the dwarf variety (SGD) was thinner weighing twice less than that of SGD x VTT coconut hybrid. All the coconut varieties had significantly $(\mathrm{p}<0.05)$ different husk weights. The WAT coconut variety had the heaviest husk weight and the SGD had the least husk weight.

Currently, the meat component of the mature coconut fruit composition is what matters most to the coconut farmer due to its economic importance. Consequently, coconut varieties in Ghana are not being selected for their husk, shell or water weights. One way to create wealth in coconut growing communities is to

Table 3: Fruit components weight of SGD x VTT and other important coconut varieties

\begin{tabular}{lccccc}
\hline Variety & \multicolumn{3}{c}{ Fruit Components } \\
\cline { 2 - 6 } & $\begin{array}{c}\text { Whole nut } \\
(\mathrm{g})\end{array}$ & $\begin{array}{c}\text { Husk } \\
(\mathrm{g})\end{array}$ & $\begin{array}{c}\text { Shell } \\
(\mathrm{g})\end{array}$ & $\begin{array}{c}\text { Meat } \\
(\mathrm{g})\end{array}$ & $\begin{array}{c}\text { Water } \\
(\mathrm{t})\end{array}$ \\
\hline SGD x VTT & $\begin{array}{c}863^{\mathrm{b}} \\
( \pm 36.3)\end{array}$ & $\begin{array}{c}255^{\mathrm{d}} \\
( \pm 13.5)\end{array}$ & $\begin{array}{c}143^{\mathrm{a}} \\
( \pm 9.6)\end{array}$ & $\begin{array}{c}306^{\mathrm{a}} \\
( \pm 15.3)\end{array}$ & $\begin{array}{c}161^{\mathrm{a}} \\
( \pm 15.9)\end{array}$ \\
& $1,032^{\mathrm{a}}$ & $373^{\mathrm{b}}$ & $170^{\mathrm{a}}$ & $337^{\mathrm{a}}$ & $151^{\mathrm{a}}$ \\
MYD x VTT & $( \pm 42.8)$ & $( \pm 27.8)$ & $( \pm 9.4)$ & $( \pm 17.3)$ & $( \pm 6.5)$ \\
& $423^{\mathrm{c}}$ & $178^{\mathrm{e}}$ & $67^{\mathrm{b}}$ & $148^{\mathrm{c}}$ & $29^{\mathrm{d}}$ \\
SGD & $( \pm 18.4)$ & $( \pm 7.3)$ & $( \pm 3.8)$ & $( \pm 8.9)$ & $( \pm 3.4)$ \\
& $829^{\mathrm{b}}$ & $327^{\mathrm{c}}$ & $144^{\mathrm{a}}$ & $269^{\mathrm{b}}$ & $90^{\mathrm{b}}$ \\
VTT & $( \pm 17.8)$ & $( \pm 11.8)$ & $( \pm 3.6)$ & $( \pm 7.9)$ & $( \pm 6.1)$ \\
& $873^{\mathrm{b}}$ & $414^{\mathrm{a}}$ & $142^{\mathrm{a}}$ & $247^{\mathrm{b}}$ & $70^{\mathrm{c}}$ \\
WAT & $( \pm 21.4)$ & $( \pm 11.4)$ & $( \pm 3.3)$ & $( \pm 6.9)$ & $( \pm 4.2)$ \\
& 45.1 & 44.3 & 30.2 & 35.5 & 18.6 \\
LSD 0.05 & & & & \\
\hline
\end{tabular}

Means in the same column followed by the same letter $(\mathrm{s})$ are not significantly different $(\mathrm{P}<0.05)$. 
diversify the coconut industry by introducing small scale processing technologies to add value to the many identifiable parts of the coconut for both domestic and export markets. Some of these new technologies allow for the commercial production of virgin coconut oil from the meat, ropes and doormats from the husk, vinegar and sugar from the water, handicraft and activated charcoal from the shell (Luisito, 2007; Osei-Bonsu et al., 2008).

\section{CONCLUSION \& RECOMMENDATIONS}

The study indicated that the SGD x VTT coconut hybrid like its counterpart MYD x VTT came into fruition three years earlier than the tall varieties (WAT and VTT). The SGD $x$ VTT enjoyed hybrid vigour as compared with its parents: SGD and VTT. Its yield performance was better than the tall coconut types and compared favourably with the MYD $x$ VTT which was previously used by the Coconut Sector Development Project for replanting of coconut farms devastated by the Cape St Paul Wilt Disease (CSPWD) but which succumbed under high disease pressure as it was semi-tolerant. The good agronomic characteristics of the SGD x VTT as shown by this study coupled with its high resistance to the CSPWD proved its suitability as alternative planting material to revamp the coconut industry in Ghana

It is recommended that the SGD $\mathrm{x}$ VTT is evaluated for its oil content and quality for eventual release as a hybrid to be produced for farmers in Ghana.

\section{ACKNOWLEDGMENT}

The coconut plots used for the study were established through funding support given by the World Bank/ Government of Ghana through the National Agricultural Research Project (NARP) and the French Government through the French Technical co-operation for which the authors hereby acknowledge. The field assistance offered in the area of data collection by Messrs John Ediyie and Joseph Martin Bannerman and Madam Elizabeth Adjei of OPRI Coconut Research Programme is duly recognized.

\section{REFERENCES}

Adam, M., Arthur, R., Duhamel, G., Ghartery, N., Overfield, D. and Willougby, N. (1996). Analysis of natural resource utilization, livelihoods systems coping strategies and natural resource research needs in coconut growing areas of the coastal zone ecosystems in Ghana. NRI DOC CO834, Vol. 1, Main report.

Andoh-Mensah, E., Bonneau, X., Nuertey, B. N. and Dery, S. K. (2003). Effect of mineral nutrition on nut yield and fruit composition of mature coconut palms in the coastal belt of Western Region of Ghana Preliminary Studies. Cord Vol. XIX No. 2, 11-15.

Bourdeix, R. (1999). Coconut varieties: Malayan dwarf. IPGRI - COGENT News letter, October 1999, issue No. 2, 13- 15.

Dery, S. K., N'cho, Y.P., Sangaré, A. and Arkhurst, E. D. (1997). Cape St. Paul Wilt Disease: Resistance screening and prospects for rehabilitating the coconut Industry in Ghana. In: Eden Green, S. J. and Ofori, F. (Editors). Proceedings of an international workshop on lethal yellow ing - like disease of coconut, Elmina, Ghana. November 1995, Chatman, UK, Natural Resources Institute. 147 - 151.

Dery, S. K., Philippe, R., Baudouin, L., Quaicoe, R. N., Nkansah Poku J., Owusu-Nipah, J., Arthur, R., Dare, D., Yankey, N. and Dollet, M. (2008). Genetic diversity among coconut varieties for susceptibility to CSPWD. Euphytica 164:1-11

FAO (1975). Coconut Palm Products: Their Processing in Developing Countries. Tropical Products Institute, London, 6 $-29$

Luisito, J. P. (2007). Production of handicrafts, wares and novelty items from coconut wood, fronds and coconut fruit residues. 


\section{Dare et al.}

CORD 23 (2): 84-91.

Ofori, F. and Nkansah - Poku, J. (1997). Cape St. Paul Wilt Disease of coconut in Ghana - History of its occurrence and spread. In: Eden Green, S.J. and Ofori, F. (Editors). Proceedings of an international workshop on lethal yellowing like disease of coconut, Elmina, Ghana. November 1995. Chatman, UK. Natural Resources Institute. 147 - 151.

Ohler, J. G. and Magat, S. S. (2001). Cocos nucifera L. In: Van der Vossen, H. A. M. and Umali, B. E. (Editors). Plant resources of South - East Asia No. 14.
Vegetable oils and fats. Backhuys Publishers, Leiden, the Netherlands. 76 - 84.

Osei - Bonsu, A., Jayashree, K., Swanzy, F., Yankey, N., Danso, I. and Kukuri, M. (2008). Food security and nutrition in coconut based - households: A case study of Nvuma, Ghana. Journal of Ghana Sci. Assoc. 10 (2): $158-165$

Santos, G. A., Batugal, P.A., Othman, A., Baudouin, L. and Laboisse, J. P. (Editors) (1996). Manual on standardized research techniques in coconut breeding. IPGRIAPO, Serdang, Malaysia, 46pp. 